Article

\title{
Influence on Bone-to-Implant Contact of Non-Thermal Low-Pressure Argon Plasma: An Experimental Study in Rats
}

\author{
Arturo Sanchez-Perez ${ }^{1}$, Ana I. Nicolas-Silvente ${ }^{2, *}{ }^{\mathbb{D}}$, , Carmen Sanchez-Matas ${ }^{3}$, \\ Fernando Muñoz-Guzon ${ }^{4}(0)$, Carlos Navarro-Cuellar ${ }^{5}$ and Georgios E. Romanos ${ }^{6}$ \\ 1 Department of Periodontology, Medicine and Dentistry Faculty, Murcia University, 30008 Murcia, Spain; \\ arturosa@um.es \\ 2 Department of Restorative Dentistry, Medicine and Dentistry Faculty, Murcia University, 30008 Murcia, Spain \\ 3 Virgen del Rocio Hospital, 41013 Sevilla, Spain; nem.csm@gmail.com \\ 4 Veterinary School, University of Santiago de Compostela, 27002 Lugo, Spain; fernandom.munoz@usc.es \\ 5 Department of Surgery, Complutense University, 28031 Madrid, Spain; cnavarrocuellar@gmail.com \\ 6 Department of Periodontology, School of Dental Medicine, Stony Brook University, Stony Brook, \\ NY 11794-8712, USA; georgios.romanos@stonybrookmedicine.edu \\ * Correspondence: ainicolas@um.es; Tel.: +34-96824-7946
}

Received: 15 March 2020; Accepted: 25 April 2020; Published: 28 April 2020

\begin{abstract}
Roughness characteristics play an essential role in osseointegration. However, there is a concern about the susceptibility of those surfaces to bacterial colonization. New techniques for cleaning and surface treatment have appeared that could favor osseointegration without the need to create surfaces as rough. Such is the case of non-thermal low-pressure argon plasma (NTLP-ArP). One hundred and forty-four implants were placed in the tibiae of 36 Sprague Dawley rats, distributed in four experimental groups: I: mechanized surface; II: mechanized surface treated with NTLP-ArP, III: resorbable blast media (RBM) surface; and IV: RBM surface treated with (NTLP-ArP). Bone-to-implant contact (BIC) percentages were calculated by microtomographic evaluation and histological analysis at one, two, and four weeks after implant placement. ANOVA and Mann-Whitney tests were used for statistical analysis, establishing $p<0.05$. No significant differences were found at one-week comparisons. The groups treated with NTLP-ArP obtained higher BIC\% than those not treated at two and four weeks. Mechanized surfaces treated with NTLP-ArP obtained BIC values similar to RBM surfaces.
\end{abstract}

Keywords: argon plasma; bone-to-implant contact; implant dentistry; mechanized surface; osseointegration; resorbable blast media surface

\section{Introduction}

In recent years, Branemark-type implants with a mechanized surface have been considered the gold standard in modern implantology, leading to a predictable behavior [1]. However, several studies demonstrated that the biocompatibility and cell viability could be improved [2] by modifying the roughness of the implant surface using different techniques [3]. Other authors have incorporated stem cells with the same objective [4]. Furthermore, biomaterials and stem cells have been frequently combined, representing a common strategy for bone tissue engineering applications [5].

This roughness in the implant surface seems to be one of the essential factors in achieving adequate osseointegration [6,7]. The increase in roughness has been shown to lead to an increase in the bone-to-implant contact percentage (BIC) [8]. With the creation of these new surfaces, the time needed to achieve osseointegration was reduced due to the improvement in osteoconduction and 
osteogenesis [9]. It was even postulated that the increase in roughness could prevent bone loss [10]. However, other authors expressed concern about the greater susceptibility of these rough surfaces to bacterial contamination [11]. Regardless of the degree of roughness, another factor to consider is that the implant surfaces undergo changes from their manufacture to their clinical use.

One procedure proposed to improve the implant surface is based on non-thermal low-pressure argon plasma (NTLP-ArP) [12]. Some authors have already shown that NTLP-ArP is capable of enhancing the implant surface characteristics, and therefore, the earliest biological response without altering the original topography [13].

One interesting strategy to be evaluated by the industry would be the development of mechanized surfaces to which we can confer high osseointegration capacity. The mechanized surface would receive a surface treatment that does not modify its roughness but significantly improves the osseointegration capacity. With these characteristics, we would obtain better behavior against peri-implant diseases by not having a rough surface. The possibilities of effective treatment and simple maintenance would be increased.

Our null hypothesis was that NTLP-ArP does not represent an improvement in terms of BIC values compared to surfaces treated and not treated with resorbable blast media (RBM). The alternative hypothesis was the existence of differences between using or not using NTLP-ArP on both surfaces.

\section{Material and Methods}

\subsection{Sample Description}

Animal experiments were conducted with 36 female adult Sprague Dawley rats with a mean weight of $619 \mathrm{~g}$ ( $478 \mathrm{~g}$ to $767 \mathrm{~g}$ ) from the animal housing facilities of the University of Santiago de Compostela (Spain). Each rat was identified with a number on an ear. This study was developed in strict accordance with the guidelines for the use of animals for experimentation purposes [14]. The study was approved by the ethics committee of the University of Santiago de Compostela (Spain). The principles of replacement reuse and reduction were observed, and all personnel in charge of the experimental work were vetted for their qualifications.

\subsection{Animals Keeping}

Animals were kept in individual cages in a room with photoperiod, air renewal, and regulated temperature and humidity. They were fed with a specific granulated diet for its species and free water supply.

\subsection{Implant Features}

144 Ticare screw-type implants with a diameter of $1 \mathrm{~mm}$ and length of $3 \mathrm{~mm}$ were used (Ticare, Mozo-Grau, Valladolid, Spain). A total of 72 implants presented a mechanized surface and 72 implants a surface treated by resorbable blast media (RBM) (Ticare, Mozo-Grau, Valladolid, Spain). Half of them (36 mechanized and $36 \mathrm{RBM}$ ) received a surface treatment with a non-thermal low-pressure argon plasma, and the other half were placed as received by the manufacturer; thus, four experimental groups were established:

- $\quad$ Group I (M): $(\mathrm{n}=36)$ Mechanized implants.

- Group II (M-P): $(\mathrm{n}=36)$ Mechanized implants treated with non-thermal low-pressure argon plasma.

- $\quad$ Group III (RBM): $(\mathrm{n}=36) \mathrm{RBM}$ implants.

- $\quad$ Group IV (RBM-P): $(\mathrm{n}=36) \mathrm{RBM}$ implants treated with non-thermal low-pressure argon plasma. 


\subsection{Randomization}

Before surgery, a randomization sequence was performed using a computer application [15] and the results were concealed until surgery. After anesthetizing the animal, the implants were placed following the random order established by the app, always producing the same repetitions per position and side.

\subsection{Surgery Protocol}

All surgical procedures were performed under sterile conditions in an operating room and general anesthesia using isofluorane at a concentration of $1 \%-3 \%$ and oxygen with a mask. Before surgery, each rat was premedicated with medetomidine intramuscular (i.m.) $50-100 \mu \mathrm{m} / \mathrm{kg}$, ketamine i.m. $75-100 \mathrm{mg} / \mathrm{kg}$, buprenorphine subcutaneous (s.c.) $0.01-0.05 \mathrm{mg} / \mathrm{kg}$ and induced by isoflurane chamber. Animals were monitored during the surgery intervention by an accredited veterinarian trained in laboratory animal science (category B).

After sedation and anesthesia, epilation and surgical cleaning of the skin with chlorhexidine $5 \mathrm{mg} / \mathrm{mL}$ in $70 \%$ ethanol were performed. A medial approach to the metaphysis was made of both tibias through an anteromedial skin incision. Skin and periosteum were reflected using periosteal elevators and separators. In the proximal area of each tibia, two titanium implants were placed after drilling with an increasing diameter drills technique. The incision was sutured in layers with a 5-0 resorbable suture. Antibiotic prophylaxis was administered with enrofloxacin, $100 \mathrm{mg} / \mathrm{liter}$ of drinking water. Water was changed on a daily basis. Animals were protected from light for three weeks.

Postoperatively, the pain was controlled with buprenorphine for three days and meloxicam as an analgesic for five days, following the animal study protocol USC-Lugo FMG rats Mozo-Grau 2016.

\subsection{Euthanasia}

Each experimental group was randomly subdivided into three groups so that the animals were euthanized one week, two weeks, and four weeks after surgery, depending on the group assigned. All animals were euthanized by an overdose of pentobarbital (40-60 mg/Kg/I.V.), and tibia biopsies were obtained for histological processing.

\subsection{Sample Processing}

\subsubsection{Sample Preparation}

Tibias were dissected, and bone blocks containing implants were obtained. The bone blocks were fixed with a $10 \%$ buffered formaldehyde solution for seven days at $4{ }^{\circ} \mathrm{C}$. Each sample was coded with a number from 1 to 36 , which indicated the animal, and two letters, the first letter referring to the location of the limb, being right or left ( $\mathrm{R}$ or $\mathrm{L}$ ), and the second letter indicating the position of the implant, being proximal or distal (P or D).

\subsubsection{Microtomography}

The samples were scanned using high-resolution computerized microtomography equipment (Skyscan 1172, Bruker microCT NV, Kontig, Belgium). To capture the images, a $1 \mathrm{~mm}$ thick aluminum filter was used, and the parameters used were $80 \mathrm{Kv}$ and $124 \mu \mathrm{A}$ with a pixel size of $6 \mu \mathrm{m}$. The samples were wrapped in formalin soaked gauzed inside an Eppendorf tube. The canning was carried out with a rotation of $360^{\circ}$, and the acquisition of the images was every $0.4^{\circ}$. Image reconstruction was carried out by Feldfamp's algorithm using NRecon reconstruction software (Bruker microCT NV, Kontig, Belgium). The same parameters for all samples were used, being: Histogram 0-030; Smoothing: 2; Beam hardening: 25\% and Ring artifact correction: 5 .

The images were divided into two sections: cortical and medullar. Due to the large medullar cavity, this area was not considered in this study. The analysis of the cortical portion was performed 
with the help of Data Viewer Software (Bruker microCT NV, Kontig, Belgium). The cortical surface was positioned as parallel as possible regardless of the implant placement, and the volume of interest (VOI) was selected. In this study, only VOIs were considered where the complete cortical appeared: both the proximal and the distal part of the implant must appear surrounded entirely by cortical bone. Once the regions of interest were selected, data were analyzed using CTAn with a threshold of 80-255 for the implant and 30-255 for hard tissue (implant + bone). Bone-to-implant contact (BIC) was evaluated for each sample (Figure 1).

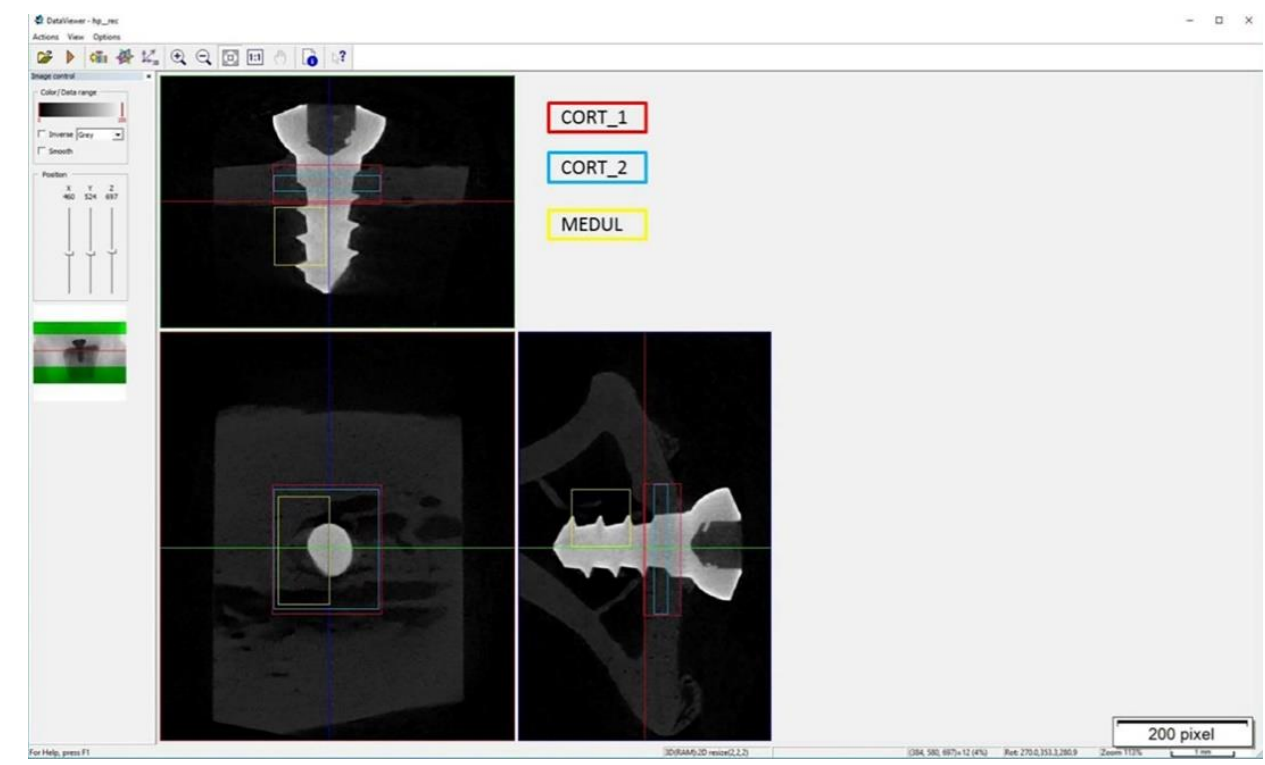

Figure 1. Evaluation on one sample by Data Viewer Software for measuring bone-to-implant contact (BIC) (cortical and medullar).

\subsubsection{Histological Preparation}

\section{- $\quad$ Block preparation}

After cutting the specimens into smaller fragments, the blocks were dehydrated in increasing concentrations of alcohol (80\%, 96\%, 100\%, and 100\%) every two days. Inclusion was performed on a reciprocating shaker using a light-curing glycolmethacrylate based resin (Technovit 7200 VLC; Heraeus-Kulzer GMBH, Wertheim, Germany) at increasing concentrations in alcoholic solution every two days. The polymerization took place using high-intensity blue light with specific equipment.

- $\quad$ Sheet preparation and evaluation

The blocks obtained were sectioned and roughened using Exakt system machinery (Exakt Aparatebau GMBH, Norderstedt, Germany). Once the thin sheets were sliced, they were stained by Levai Laczko staining. Stained sections were digitally photographed at $40 \times$ using a powered stage light microscope with a digital camera (BX51, DP71; Olympus Corporation, Tokyo, Japan). Images were colored using a digital tablet and image treatment software (Photoshop, Adobe, San Jose, CA, USA), differentiating the implant, bone, and soft tissue.

The results were quantified through an image analysis program (CellSens, Olympus Corporation, Tokyo, Japan) by an observer blind to the type of implant. The surface in contact with mineralized bone was called bone-to-implant contact (BIC) and was calculated as a percentage.

\subsection{Statistical Analysis}

The means, standard deviations, and medians of all the data were calculated using the statistical analysis software Sigma Plot 12.5 (Softonic International, Barcelona, Spain). Differences between 
experimental groups were analyzed using a one-way analysis of variance (ANOVA). The normality was verified through the Shapiro-Wilk test. The Mann-Whitney test was used to discern differences for continuous variables. Significant differences were considered with $p<0.05$.

\section{Results}

During the experimental period, there were no unexpected deaths. Animals that bit the suture, had a wound exposed, or had part of the skin removed from the area were selected to be part of the group that was euthanized one week after implant placement. No problems were found during the final sampling, and all the implants could be recovered.

Regarding the microtomography analysis, no significant difference was observed between the experimental groups.

In results at one week, when we used non-thermal low-pressure argon plasma (NTLP-ArP) on a mechanized surface, the BIC \% was improved; on the other hand, on RBM surfaces we did not obtain an improvement. However, these differences had no statistically significant difference.

In the second week, our results showed lower BIC\% values when NTLP-ArP was used on both surfaces.

The results in the fourth week showed somewhat higher BIC values when NTLP-ArP was applied. Group IV (RBM-P) showed higher BIC values than the rest of the groups. However, no statistically significant difference was observed between groups or between time intervals $(p<0.05)$ (Table 1$)$ (Figure 2).

Table 1. BIC percentages and standard deviation of each experimental group obtained by microtomography at 1,2, and 4 weeks. No statistically significant difference was observed between groups or between time intervals taking into account the significance value of $p<0.05$.

\begin{tabular}{cccccccc}
\hline \multirow{2}{*}{$\begin{array}{c}\text { Experimental } \\
\text { Group }\end{array}$} & \multirow{n}{*}{} & \multicolumn{2}{c}{$\mathbf{1}$ Week } & \multicolumn{2}{c}{ 2 Weeks } & \multicolumn{2}{c}{ 4 Weeks } \\
\cline { 3 - 7 } & & BIC (\%) & C.I. 95\% & BIC (\%) & C.I. 95\% & BIC (\%) & C.I. 95\% \\
\hline I (M) & 12 & 70.67 & $61.09-80.25$ & 76.97 & $73.42-80.52$ & 76.16 & $71.05-81.27$ \\
II (M-P) & 12 & 75.52 & $71.73-79.31$ & 73.48 & $70.09-76.87$ & 77.92 & $73.34-82.50$ \\
III (RBM) & 12 & 77.85 & $74.38-81.38$ & 75.60 & $72.11-79.09$ & 75.81 & $71.48-80.14$ \\
IV (RBM-P) & 12 & 73.78 & $68.13-79.43$ & 74.83 & $69.61-80.05$ & 78.80 & $72.95-84.65$ \\
\hline
\end{tabular}

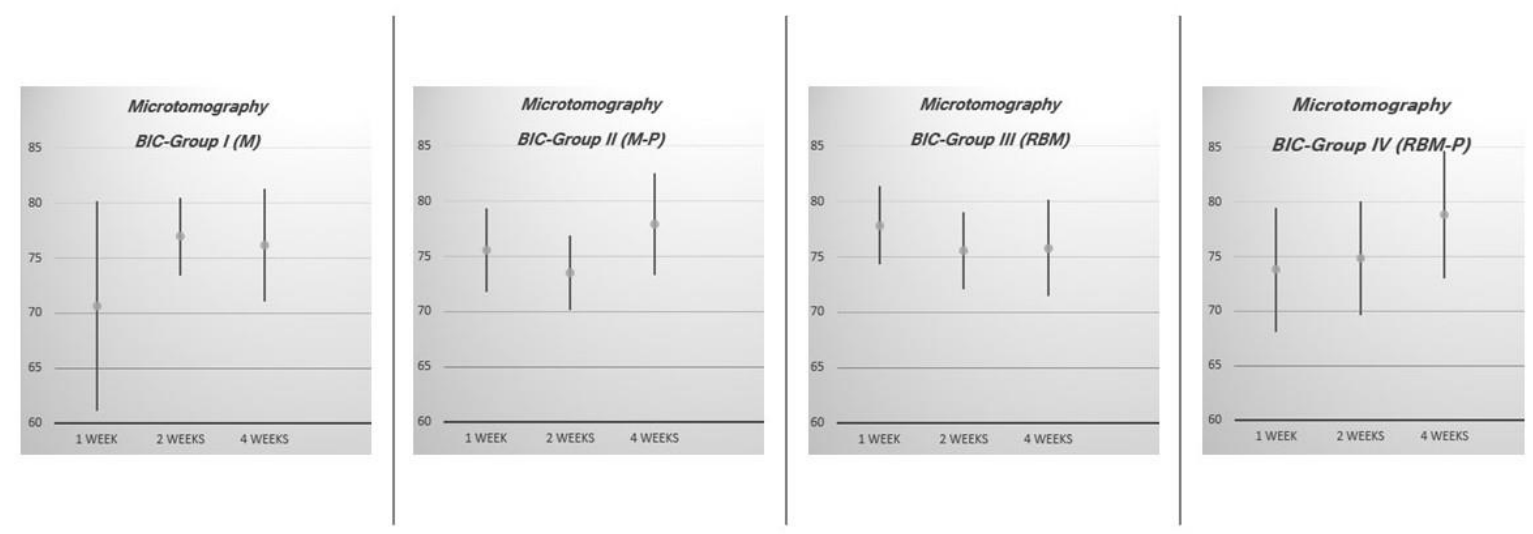

Figure 2. BIC percentages with the C.I. (95\%) of each experimental group obtained by microtomography at 1,2 and 4 weeks.

The most significant differences were observed when carrying out the histological study (Figure 3). At one week, our results did not show differences with a statistical significance $(p<0.05)$, although the RBM and RBM-P groups showed higher values. 
At two weeks, both surfaces, mechanized and RBM, showed better BIC when they were treated with NTLP-ArP, showing statistical differences between groups I and II ( $p=0.018)$, between groups I and IV $(p=0.001)$. Statistical differences also appeared between groups III and IV $(p=0.035)$.

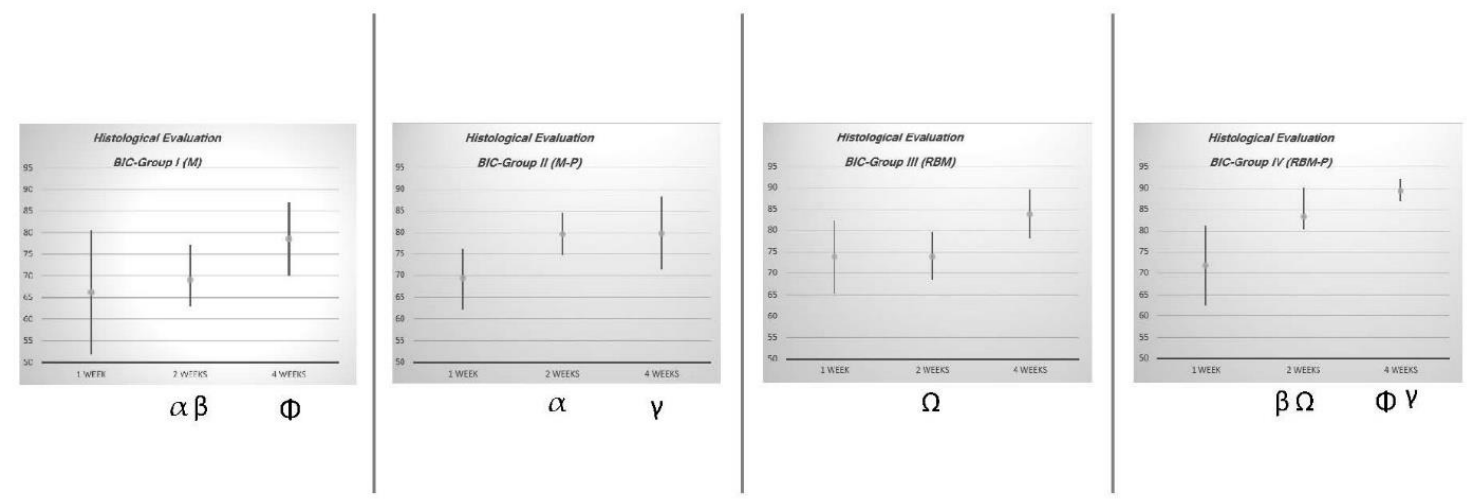

Figure 3. Histological preparations at one, two, and four weeks after implant placement.

At four weeks, no differences were found on the mechanized surface when treated or not treated with NTLP-ArP (groups I and II). On RBM surfaces, higher BIC was found when treated with NTLP-ArP showing statistical differences when comparing group IV with groups I ( $p=0.018)$ and with group II $(p=0.024)$ (Table 2) (Figure 4).

Table 2. BIC percentages and standard deviations of each experimental group obtained by histological evaluation at one, two, and four weeks. No statistically significant difference was observed between groups in the first week $(p<0.05)$. At two weeks, there were significant differences between $(\alpha)$ : M and M-P ( $p=0.018) ;(\beta)$ : M and RBM-P ( $p=0.001)$; and $(\Omega)$ : RBM and RBM-P $(p=0.035)$. At four weeks, significant differences appeared between $(\Phi)$ M and RBM-P $(p=0.018)$ and $(\gamma)$ M-P and RBM-P $(p=0.024)$.

\begin{tabular}{cccccccc}
\hline \multirow{2}{*}{$\begin{array}{c}\text { Experimental } \\
\text { Group }\end{array}$} & $\mathbf{n}$ & \multicolumn{2}{c}{ 1 Week } & \multicolumn{2}{c}{ 2 Weeks } & \multicolumn{2}{c}{ 4 Weeks } \\
\cline { 3 - 7 } & & BIC (\%) & C.I. 95\% & BIC (\%) & C.I. 95\% & BIC (\%) & C.I. 95\% \\
\hline I (M) & 12 & 66.20 & $51.89-80.51$ & $69.06 \alpha \beta$ & $62.93-77.19$ & $78.56 \Phi$ & $70.10-87.02$ \\
II (M-P) & 12 & 69.27 & $62.20-76.34$ & $79.66 \alpha$ & $74.75-84.57$ & $79.92 \gamma$ & $71.46-88.38$ \\
III (RBM) & 12 & 73.90 & $65.27-82.53$ & $73.97 \Omega$ & $68.34-79.60$ & 83.91 & $78.20-89.62$ \\
IV (RBM-P) & 12 & 71.92 & $62.55-81.29$ & $83.35 \beta \Omega$ & $80.47-90.23$ & $89.49 \Phi \gamma$ & $86.82-92.16$ \\
\hline
\end{tabular}

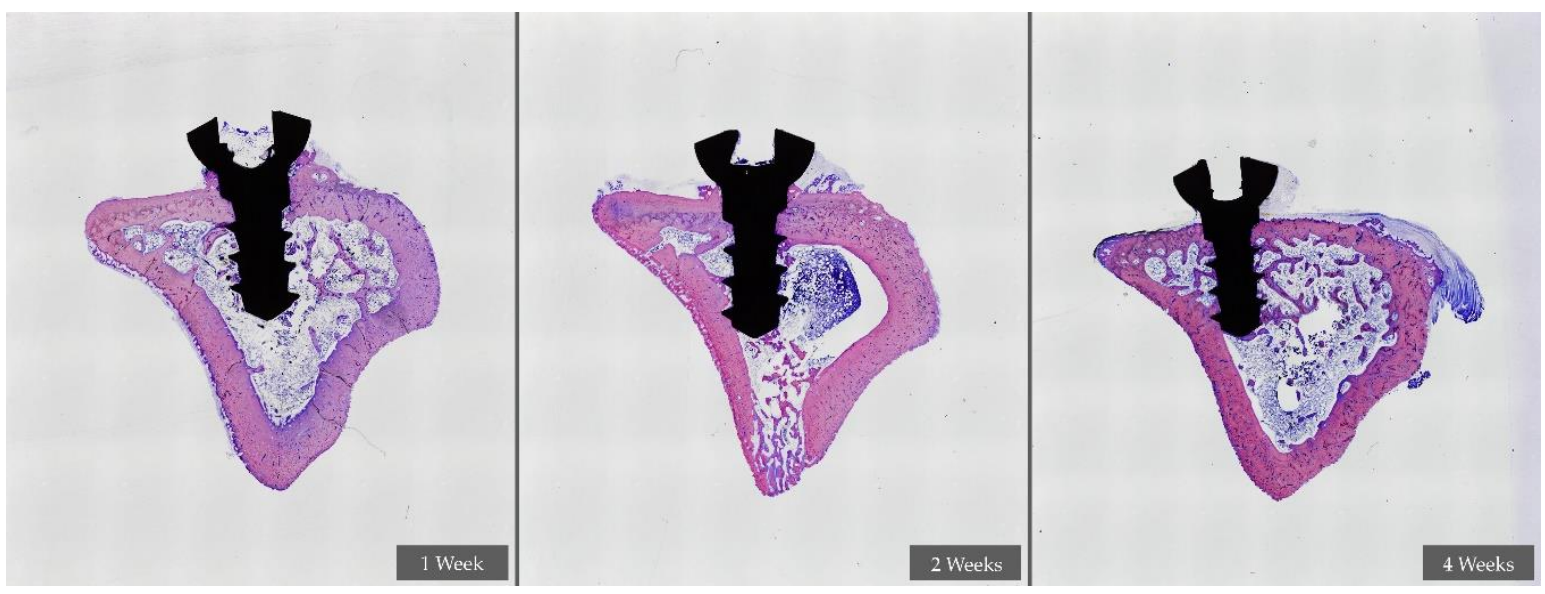

Figure 4. BIC percentages with the C.I. (95\%) of each experimental group obtained by histological evaluation at one, two, and four weeks. $p$ values $=(\alpha) 0.018 ;(\beta) 0.001 ;(\Omega) 0.035 ;(\Phi) 0.018 ;(\gamma) 0.024$. 


\section{Discussion}

The present study aimed to evaluate the influence on the bone-to-implant contact (BIC) of non-thermal low-pressure argon plasma (NTLP-ArP) over two different implant surfaces: a mechanized implant surface, with a smooth surface $(\mathrm{Ra}<0.5 \mu \mathrm{m})$ and a resorbable blast media $(\mathrm{RBM})$ surface that was moderately rough $(\operatorname{Ra} 1.0-2.0 \mu \mathrm{m})$ [16].

It is widely known that the osteoblast activity is increased with micro-roughness ranging between 1 and $100 \mu \mathrm{m}$ when compared with untreated or smooth surfaces [17]. This is the reason why the industry develops new surface treatment techniques to achieve adequate topography, roughness, or chemical composition characteristics to improve cell viability and biocompatibility [2].

Regarding the chemical composition, Velasco-Ortega et al. [18] showed that the $\mathrm{TiO}_{2}$ surface treatment and composition influence the wettability and surface free energy, affecting the protein adsorption. In the cited study, the machined (smooth) surface showed a minimal area occupied by cells or connective tissue growing around. In addition, the cells cultured on rougher surfaces presented attributes of more differentiated osteoblasts [18].

However, these new surfaces which allow quick osseointegration present some disadvantages, like the presence of trace elements, such as metals, ions, detergents, or lubricants deposited on the surface [19] that may affect the body's response during the osseointegration process, leading to the undesirable formation of inflammatory tissue surrounding the implant [20,21].

Recent research lines suggest the use of some techniques capable of enhancing the surface characteristics without modifying the topography or roughness features, as is the case with NTLP-ArP.

Osseointegration represents a dynamic process both during its establishment and its maintenance. Several factors have been related to primary stability during the establishment phase, including local bone quality and quantity, and implant macro-design [22-24]. All of these come together in an adequate primary stability.

In the early phase, the macro-design of the implant plays an essential role in primary stability. This primary stability is due to the strong contact and friction between the thread shape and the bone [25]. The bone formation begins with the angiogenesis process, and is initiated in the concavities rather than convexities of the implant threads due to the higher concentration of vessels inside these concavities. However, the precise mechanism is not yet completely elucidated. It seems that because the environment formed inside the cavities promotes mechanical forces, the concentration of gradients of chemotactic molecules and blood clot retention could drive vascular and bone cell migration [26].

The space created between the threads (called the chamber) is filled by the blood clot that is progressively replaced by a connective matrix with mesenchymal cells and surrounded by blood vessels [27].

The thread geometry not only affects the distribution of stress forces around the implant, but it also directly influences the size of the chamber and, indirectly, the bone healing. Therefore, the width, the length, and the thread shape all play an important role $[28,29]$.

In general, bone healing phases have been studied in animal models [25,30-34]. In human studies, it was shown that the percentage of newly formed bone attached to the implant surface increased with time $[35,36]$.

One week after insertion, the osteoid deposit can be observed with areas of newly formed bone. This new bone gradually increases during the second week with the presence of osteoblasts and blood vessels. Meanwhile, in some pitch regions of the thread (areas that were responsible for primary mechanical stability), the bone tissue exhibited signs of bone remodeling [25].

Some studies have evaluated how the microtopography may affect the cellular response showing that local tissue growth is proportional to the substrate curvature, directly affecting the osteoblast behavior [37]. Magnaudeix et al. demonstrated in an in vivo study that the pore geometry influences colonization by blood vessels, due to the pore size and shape having a critical role in guiding cell behavior [38]. This influence was also demonstrated by Juignet et al. [39] in an in vitro study growing mouse calvaria cells over hydroxyapatite ceramics with different macro groove shapes, which found 
that the organization and growth are promoted by a tight closure angle of the substrate geometry. These authors described higher numbers of cells attached to grooved ceramics compared to flat controls, suggesting that the microarchitecture promoted adhesion to the surface. These results are in agreement with our findings when comparing the two surfaces (mechanized and RBM) without NTLP-ArP treatment. The results also agree when comparing both surfaces after NTLP-ArP treatment, demonstrating that the micromorphology affects the BIC values. Nonetheless, the micromorphology not only influences the tissue response but also the physical stimuli produced on the surface by NTLP-ArP without altering the surface topography.

The most important factors affecting the complex process of the integration of dental implants to the alveolar bone are the physical and chemical properties of the surface of the dental implant. Thus, the surface of a dental implant possesses important characteristics that play a crucial role in bone deposition and consequent healing and osseointegration.

The development of NTLP-ArP allows for cleaning the implant surface while modifying the surface properties without altering their micro-design [40]. This improvement has meant that mechanized surfaces can have a potential for osseointegration similar to that of rough surfaces, but without their drawbacks.

Our study focused on demonstrating whether there were differences between mechanized implant surfaces and those treated with RBM, both of them treated or not with NTLP-ArP, by comparing the BIC\% at three different time intervals: one week, two weeks, and four weeks after implant placement. Our results showed better BIC\% when the surfaces were treated with NTLP-ArP in both mechanized and RBM surfaces. Surprisingly, the results of the mechanized surfaces treated with NTLP-ArP were similar to RBM surfaces without plasma in BIC values.

The data obtained in this study are in agreement with other results published in previous animal studies, where NTLP-ArP has been shown to improve the properties of implant surfaces [41], as well as other studies that confirm the results obtained in cell cultures $[13,42]$.

The fact to highlight in our results is that the behavior of every experimental group was similar during the first week. This may be explained due to the nonspecific healing that occurred in the initial stages. These results improved both in the second and the fourth week. The differences between the experimental groups again underscore the improvement with NTLP-ArP application in both surfaces, mechanized and resorbable blast media (RBM), at any point in time.

Finally, it should be mentioned that the beneficial effects of NTLP-ArP not only appear on titanium surfaces but have also been described on different substrates $[31,35,36]$.

Scarano et al. also evaluated the effect of thermal treatment of Ti6Al4V dental implants on bone healing in rabbits, showing results in agreement with our statements, and concluding that the surfaces modified by thermal treatment improve the bioactivity and BIC, a fact that clinically means a shortening in the implant healing period, especially in areas with low-density bone [43].

Our study could present some limitations, such as the rapid healing in animals, which can make a difference to humans. It is also limited by the follow-up time, which, in our case, lasted up to four weeks. It would be interesting to evaluate the results at a longer follow-up time to check the stability of the results. Another future research issue would be the induction of peri-implantitis, to assess the resistance to infection and the effectiveness of the treatment by the use of NTLP-ArP.

\section{Conclusions}

Taking into account the limitations of our study, we confirm our alternative hypothesis with the existence of differences between using or not using NTLP-ArP on both surfaces, and we can conclude that:

- In the first week of healing, the application of NTLP-ArP over the implant surface does not represent any improvement among the experimental groups.

- At two weeks of healing, the groups treated with NTLP-ArP obtained higher BIC values. 
- At two weeks of healing, the mechanized surface treated with NTLP-ArP obtained similar BIC values as the RBM surface.

- At four weeks of healing, the RBM-P group obtained the highest BIC values compared to the other experimental groups

- $\quad$ These results should be implemented and verified with human clinical trials.

Author Contributions: All authors have read and agreed to the published version of the manuscript. Conceptualization, A.S.-P.; methodology, A.S.-P., F.M.-G. and C.N.-C.; validation, C.S.-M. and A.I.N.-S.; formal analysis, F.M.-G.; investigation, A.S.-P. and A.I.N.-S.; resources A.S.-P.; data curation, F.M.-G. and C.N.-C.; writing-original draft preparation, A.I.N.-S.; writing—review and editing, A.S.-P and G.E.R.; visualization, G.E.R. and A.S.-P.; supervision, G.E.R. and A.S.-P.; project administration, A.S.-P.; funding acquisition, A.S.-P.

Funding: This research received no external funding.

Conflicts of Interest: The authors declare no conflicts of interest.

\section{References}

1. Buser, D.; Sennerby, L.; De Bruyn, H. Modern implant dentistry based on osseointegration: 50 years of progress, current trends and open questions. Periodontol. 2000 2017, 73, 7-21. [CrossRef] [PubMed]

2. Aparicio, C.; Rodriguez, D.; Gil, F.J. Variation of roughness and adhesion strength of deposited apatite layers on titanium dental implants. Mater. Sci. Eng. C 2011, 31, 320-324. [CrossRef]

3. Zizzari, V.L.; Marconi, G.D.; De Colli, M.; Zara, S.; Zavan, B.; Salini, V.; Fontana, A.; Cataldi, A.; Piatelli, A. In vitro behavior of primary human osteoblast onto microrough titanium surface. Impl. Dent. 2015, 24, 377-383. [CrossRef] [PubMed]

4. Diomede, F.; D’Aurora, M.; Gugliandolo, A.; Merciaro, I.; Ettore, V.; Bramanti, A.; Piatelli, A.; Gatta, V.; Mazzon, E.; Fontana, A.; et al. A novel role in skeletal segment regeneration of extracellular vesicles released from periodontal-ligament stem cells. Int. J. Nanomed. 2018, 13, 3805-3825. [CrossRef] [PubMed]

5. Diomede, F.; D’Aurora, M.; Gugliandolo, A.; Merciaro, I.; Orsini, T.; Gatta, V.; Piatelli, A.; Trubiani, O.; Mazzon, E. Biofunctionalized scaffold in bone tissue repair. Int. J. Mol. Sci. 2018, 19, 1022. [CrossRef]

6. Wennerberg, A.; Albrektsson, T. Effects of titanium surface topography on bone integration: A systematic review. Clin. Oral Implants Res. 2009, 20, 172-184. [CrossRef]

7. Wennerberg, A.; Albrektsson, T. On implant surfaces: A review of current knowledge and opinions. Int. J. Oral Maxillofac. Implants 2010, 25, 63-74.

8. Shibli, J.A.; Grassi, S.; de Figueiredo, L.C. Influence of implant surface topography on early osseointegration: A histological study in human jaws. J. Biomed. Mater. Res. B Appl. Biomater. 2007, 80, 377-385. [CrossRef]

9. Cooper, L.F. A role for surface topography in creating and maintaining bone at titanium endosseous implants. J. Prosthet. Dent. 2000, 84, 522-534. [CrossRef]

10. Le Guéhennec, L.; Soueidan, A.; Layrolle, P.; Amouriq, Y. Surface treatments of titanium dental implants for rapid osseointegration. Dent. Mater. Off. Publ. Acad. Dent. Mater. 2007, 23, 844-854. [CrossRef]

11. Cosyn, J.; Sabzevar, M.M.; De Wilde, P.; De Rouck, T. Two-piece implants with turned versus microtextured collars. J. Periodontol. 2007, 78, 1657-1663. [CrossRef] [PubMed]

12. Aronsson, B.O.; Lausmaa, J.; Kasemo, B. Glow discharge plasma treatment for surface cleaning and modification of metallic biomaterials. J. Biomed. Mater. Res. 1997, 35, 49-73. [CrossRef]

13. Canullo, L.; Genova, T.; Tallarico, M.; Gautier, G.; Mussano, F.; Botticelli, D. Plasma of argon affects the earliest biological response of different implant surfaces: An in vitro comparative study. J. Dent. Res. 2016, 95, 566-573. [CrossRef] [PubMed]

14. Spanish Royal Decree 53/2013 of February 1st; no.34; Official State Bulletin (BOE): Madrid, Spain, 8 February 2013; pp. 11370-11421.

15. Randomness and Integrity Systems. 2020. Available online: www.random.org (accessed on 27 April 2020).

16. Albrektsson, T.; Wennerberg, A. Oral implant surfaces: Part 1-review focusing on topographic and chemical properties of different surfaces and in vivo responses to them. Int. J. Prosthodont. 2004, 17, 536-543.

17. Von Wilmowsky, C.; Moest, T.; Nkenke, E.; Stelzle, F.; Schlegel, K.A. Implants in bone: Part I. A current overview about tissue response, surface modifications and future perspectives. Oral Maxillofac. Surg. 2014, 18, 243-257. [CrossRef] [PubMed] 
18. Velasco-Ortega, E.; Alfonso-Rodríguez, C.A.; Monsalve-Guil, L.; España-López, A.; Jiménez-Guerra, A.; Garzón, I.; Alaminos, M.; Gil, F.J. Relevant aspects in the surface properties in titanium dental implants for the cellular viability. Mater. Sci. Eng. C. 2016, 64, 1-10. [CrossRef]

19. Nicolas-Silvente, A.I.; Velasco-Ortega, E.; Ortiz-Garcia, I.; Monsalve Guil, L.; Gil, J.; Jimenez-Guerra, A. Influence of the titanium implant Surface treatment on the surface roughness and chemical composition. Materials 2020, 13, 314. [CrossRef]

20. Deppe, H.; Wolff, C.; Bauer, F.; Ruthenberg, R.; Sculean, A.; Mücke, T. Dental implant surfaces after insertion in bone: An in vitro study in four commercial implant systems. Clin. Oral Investig. 2017, 22, 1593-1600. [CrossRef]

21. Massaro, C.; Rotolo, P.; de Ricardis, F.; Milella, E.; Napoli, A.; Wieland, M. Comparative investigation of the surface properties of commercial titanium dental implants. Part I: Chemical composition. J. Mater. Sci. Mater. Med. 2002, 13, 535-548. [CrossRef]

22. Javed, F.; Romanos, G.E. The role of primary stability for successful immediate loading of dental implants. A literature review. J. Dent. 2010, 38, 612-620. [CrossRef]

23. Monje, A.; Suarez, F.; Garaicoa, C.A.; Monje, F.; Galindo-Moreno, P.; Garcia-Nogales, A.; Wang, H.L. Effect of location on primary stability and healing of dental implants. Implant Dent. 2014, 23, 69-73. [CrossRef] [PubMed]

24. Romanos, G.E.; Ciornei, G.; Jucan, A.; Malmstrom, H.; Gupta, B. In vitro assessment of primary stability of Straumann Implant designs. Clin. Implant Dent. Relat. Res. 2014, 16, 89-95. [CrossRef] [PubMed]

25. Berglundh, T.; Abrahamsson, I.; Lang, N.P.; Lindhe, J. De Novo Alveolar Bone Formation Adjacent to Endosseous Implants. Clin. Oral Implants Res. 2003, 14, 251-262. [CrossRef]

26. Scarano, A.; Perrotti, V.; Artese, L.; Degidi, M.; Degidi, D.; Piatelli, A.; Iezzi, G. Blood vessels are concentarted within the implant surface concavities: A histologic study in rabbit tibia. Odontology 2013. [CrossRef]

27. Cardaropoli, G.; Araújo, M.; Lindhe, J. Dynamics of Bone Tissue Formation in Tooth Extraction Sites. An Experimental Study in Dogs. J. Clin. Periodontol. 2003, 30, 809-818. [CrossRef]

28. Chun, H.J.; Cheong, S.Y.; Han, J.H.; Heo, S.J.; Chung, J.P.; Rhyu, I.C.; Choi, Y.C.; Baik, H.K.; Ku, Y.; Kim, M.H. Evaluation of design parameters of osseointegrated dental implants using finite element analysis. J. Oral Rehabil. 2002, 29, 565-574. [CrossRef]

29. Abuhussein, H.; Pagni, G.; Rebaudi, A.; Wang, H.L. The effect of thread pattern upon implant osseointegration: Review. Clin. Oral Implants Res. 2010, 21, 129-136. [CrossRef]

30. Abrahamsson, I.; Berglundh, T.; Linder, E.; Lang, N.P.; Lindhe, J. Early bone formation adjacent to rough and turned endosseous implant surfaces. An experimental study in the dog. Clin. Oral Implants Res. 2004, 15, 381-392. [CrossRef]

31. Buser, D.; Broggini, N.; Wieland, M.; Schenk, R.K.; Denzer, A.J.; Cochran, D.L.; Hoffmann, B.; Lussi, A.; Steinemann, S.G. Enhanced bone apposition to a chemically modified SLA titanium surface. J. Dent. Res. 2004, 83, 529-533. [CrossRef]

32. Schwarz, F.; Alcoforado, G.; Nelson, K.; Schaer, A.; Taylor, T.; Beuer, F.; Strietzel, F.P. Impact of implant-abutment connection, positioning of the machined collar/microgap, and platform switching on crestal bone level changes. Camlog foundation consensus report. Clin. Oral Implants Res. 2013, 25, 1301-1303. [CrossRef]

33. Carmagnola, D.; Abati, S.; Addis, A.; Ferrieri, G.; Chiapasco, M.; Romeo, E.; Vogel, G. Time sequence of bone healing around two implant systems in minipigs: Preliminary histologic results. Int. J. Periodontics Restor. Dent. 2009, 29, 549-555.

34. Abdel-Haq, J.; Karabuda, C.Z.; Arisan, V.; Mutlu, Z.; Kürkçü, M. Osseointegration and stability of a modified sand-blasted acid-etched implant: An experimental pilot study in sheep. Clin. Oral Implants Res. 2011, 22, 265-274. [CrossRef] [PubMed]

35. Lang, N.P.; Salvi, G.E.; Huynh-Ba, G.; Ivanovski, S.; Donos, N.; Bosshardt, D.D. Early osseointegration to hydrophilic and hydrophobic implant surfaces in humans. Clin. Oral Implants Res. 2011, 22, 349-356. [CrossRef] [PubMed]

36. Bosshardt, D.D.; Salvi, G.E.; Huynh-Ba, G.; Ivanovski, S.; Donos, N.; Lang, N.P. The role of bone debris in early healing adjacent to hydrophilic and hydrophobic implant surfaces in man. Clin. Oral Implants Res. 2011, 22, 357-364. [CrossRef] 
37. Rumpler, M.; Woesz, A.; Dunlop, J.W.; van Dongen, J.T.; Fratzl, P. The effect of geometry on three-dimensional tissue growth. J. R. Soc. Interface 2008, 5, 1173-1180. [CrossRef]

38. Magnaudeix, A.; Usseglio, J.; Lasgorceix, M.; Lalloue, F.; Damia, C.; Brie, J.; Pascaud-Mathieu, P.; Champion, E. Quantitative analysis of vascular colonization and angio-conduction in porous silicon-substituted hydroxyapatite with various pore shapes in a chick chorioallantoic membrane (CAM) model. Acta Biomater. 2016, 38, 179-189. [CrossRef]

39. Juignet, L.; Charbonnier, B.; Dumas, V.; Bouleftour, W.; Thomas, M.; Laurent, C.; Vico, L.; Douard, N.; Marchat, D.; Malaval, L. Macrotopographic closure promotes tissue growth and osteogenesis in vitro. Acta Biomater. 2017. [CrossRef]

40. Gatewood, R.R.; Cobb, C.M.; Killoy, W.J. Microbial colonization on natural tooth structure compared with smooth and plasma-sprayed dental implant surfaces. Clin. Oral Implants Res. 1993, 4, 53-64. [CrossRef]

41. Coelho, P.G.; Giro, G.; Teixeira, H.S. Argon-based atmospheric pressure plasma enhances early bone response to rough titanium surfaces. J. Biomed. Mater. Res. 2012, 100, 1901-1906. [CrossRef]

42. Duske, K.; Koban, I.; Kindel, E. Atmospheric plasma enhances wettability and cell spreading on dental implant metals. J. Clin. Periodontol. 2012, 39, 400-407. [CrossRef]

43. Scarano, A.; Crocetta, E.; Quaranta, A.; Lorusso, F. Influence of the thermal treatment to address a better osseointegration of Ti6Al4V dental implants: Histological and histomorphometrical study in a rabbit model. BioMed. Res. Int. 2018. [CrossRef]

(C) 2020 by the authors. Licensee MDPI, Basel, Switzerland. This article is an open access article distributed under the terms and conditions of the Creative Commons Attribution (CC BY) license (http://creativecommons.org/licenses/by/4.0/). 